\title{
Infestação de Amblyomma rotundatum (Koch) (Acari, Ixodidae) em sapos Bufo ictericus (Spix) (Amphibia, Bufonidae): novo registro de hospedeiro
}

\author{
Germano Woehl Jr. ${ }^{1}$
}

\begin{abstract}
Infestation of Amblyomma rotundatum (Koch) (Acari, Ixodidae) ticks on Bufo ictericus (Spix) (Amphibia, Bufonidae): new host record. A Bufo ictericus Spix, 1824 toad population $(\mathrm{N}=125)$ foraging in lighted areas in the Corupá Municipality, Santa Catarina State, was surveyed to evaluate the prevalence (percentage of infestation) and the mean infestation intensity of Amblyomma rotundatum Koch, 1844 (Acari, Ixodidae) ticks. The prevalence was of $19.2 \%$ and the mean infestation intensity was 7.4 ticks per infested toad. For the first time B. ictericus as host of $A$. rotundatum is reported.
\end{abstract}

KEY WORDS. Amblyomma rotundatum, ticks, Bufo ictericus, new host record

A ocorrência de Amblyomma rotundatum Koch, 1844 é bastante conhecida para certas espécies de bufonídeos e répteis (ROHR 1909; ARAGÃo 1936; ZUG \& ZUG 1979; LAMPO \& BAYLISS 1996; AMORIM et al. 1996, 1998). A situação taxonômica de A. rotundatum que foi esclarecida por ARAGÃo (1936), quando reconheceu que $A$. agamum era sinônima de A. rotundatum. Por outro lado, este autor referiu-se a $A$. goeldii, uma espécie próxima de $A$. rotundatum, como sendo restrita ao norte do Brasil. São parasitos de animais de sangue frio e reproduzem-se por partenogênese. Em geral, A. rotundatum comporta-se como carrapato de três hospedeiros, embora ARAGÃO (1936) tenha observado que algumas larvas podem mudar para ninfa sobre o hospedeiro.

Os resultados de infestações experimentais de A. rotundatum em sapos Bufo marinus Linnaeus, 1.758 revelaram que a ocorrência de morte dos hospedeiros é comum (ARAGÃo 1936; OBA \& SCHUMAKER 1983). LAMPO \& BAYLISS (1996) sugeriram que carrapatos podem regular a densidade de $B$. marinus na natureza.

O sapo Bufo ictericus Spix, 1.824 está distribuído nas regiões sul e sudeste do Brasil, leste do Paraguai e Misiones, na Argentina (KwET \& DI-BERNARDO 1999; FROST 2000), sendo muito abundante nas áreas urbanas das regiões de planalto, no sul do Brasil. Assim como outras espécies do gênero, B. ictericus é bastante oportunista para se alimentar, concentrando-se embaixo das lâmpadas dos postes e das janelas das casas para capturar os insetos atraídos pela luz, durante o período noturno (ZUG \& ZUG 1979; MATTISON 1994).

Nos últimos 10 anos, a população do município de Corupá, Santa Catarina, tem encontrado em seus quintais e jardins um grande número de sapos mortos,

1) Santuário Rã-bugio, Estrada Rio da Prata 523, Caixa d'Água, 89270-000 Guaramirim, Santa Catarina, Brasil. E-mail: germano@ieav.cta.br 
infestados por carrapatos. O presente estudo teve por objetivo apresentar os resultados da percentagem de sapos infestados, verificando a densidade relativa e a intensidade de infestação média numa amostragem feita na área urbanizada de Corupá. Este é o primeiro registro de ocorrência de A. rotundatum em sapos da espécie B. ictericus.

\section{MATERIAL E MÉTODOS}

Durante sete noites consecutivas, das 21:00 h até às $02: 00 \mathrm{~h}$, do dia 11 até o dia 17 de janeiro de 2001, foram percorridos, com automóvel e a pé, cerca de 50 $\mathrm{km}$ de estradas e ruas da região urbana e rural de Corupá (26⒉ $23^{\prime} \mathrm{S}, 49^{\circ} 13^{\prime} \mathrm{W}$ e altitude $100 \mathrm{~m}$ ). Na área rural, onde são poucos os postes com iluminação, a pesquisa foi feita em algumas propriedades, nos arredores das casas. Para a amostragem, foram consideradas quatro regiões do município: sudoeste, sudeste, noroeste e nordeste. O município de Corupá é cortado, de leste à oeste, pela BR-280, que serviư de referência para estabelecer os locais de amostragem. A região sudoeste abrange a área rural e inclui a estrada "Rota das Cachoeiras". A região sudeste é densamente habitada, mas as ruas não são pavimentadas e nem a maioria das casas são muradas. Já as regiões noroeste e nordeste são bastante urbanizadas e incluem a área central da cidade.

Com auxílio de uma lanterna, todos os sapos $B$. ictericus encontrados eram cuidadosamente examinados, sexados, medidos e, logo em seguida, soltos. Para não amostrar o mesmo sapo, cada rua foi percorrida uma única vez, pois a medida em que os sapos eram encontrados com carrapatos, estes eram removidos. Os carrapatos foram fixados em etanol a 70\% e posteriormente encaminhados ao Instituto Osvaldo Cruz (IOC) para identificação. O material foi identificado com base na chave dicotômica de ARAGÃo \& FONSECA (1961) e está depositado na Coleção Ixodológica do IOC, Rio de Janeiro, Brasil, sob número 0421. Os carrapatos não foram separados por estágios biológicos. Na identificação do hospedeiro, foi utilizada a descrição de KWET \& Di-BERNARDO (1999) e HEYER et al. (1990).

\section{RESULTADOS E DISCUSSÃO}

Ao todo foram examinados 125 sapos B. ictericus (68\% fêmeas e 34\% machos), dos quais 13 fêmeas e 11 machos estavam parasitados. Os carrapatos coletados $(\mathrm{N}=178)$ foram identificados como pertencentes à espécie $A$. rotundatum.

A tabela I apresenta o número de B. ictericus examinados e infestados, número de carrapatos coletados, densidade relativa (número de carrapatos/número de sapos examinados) e intensidade de infestação média (número de carrapatos/número de sapos infestados) para cada região estudada. O menor exemplar encontrado de sapo B. ictericus infestado com carrapatos $(\mathrm{n}=13)$ mediu $55 \mathrm{~mm}$ e era uma fêmea jovem; o maior exemplar com carrapato $(n=1)$ foi um exemplar macho adulto, que mediu $122 \mathrm{~mm}$. Uma fêmea de B. ictericus, medindo $81 \mathrm{~mm}$ (Fig. 1), foi encontrada, na região sudoeste, com uma infestação de 61 carrapatos. Os maiores índices de infestação, durante o período de estudo, foram verificados na região sudoeste, que abrange a área rural. No presente estudo, levando-se em conta toda as regiões, a infestação nas fêmeas (fêmeas parasitadas/fêmeas examinadas) foi de $16 \%$ e a 


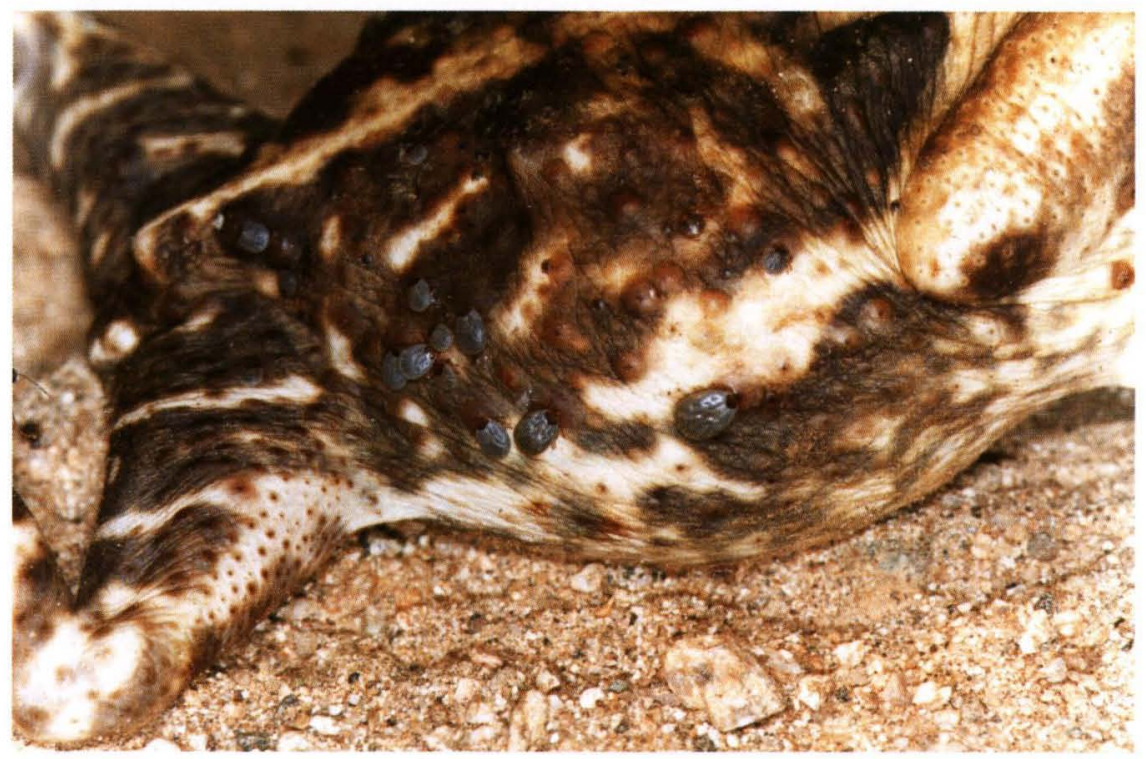

Fig. 1. Fêmea de Bufo ictericus, com $81 \mathrm{~mm}$ de comprimento rostro-anal, encontrada em Corupá, Santa Catarina, infestada de carrapatos Amblyomma rotundatum.

Tabela I. Índices de infestação do carrapato Amblyomma rotundatum em sapos Bufo ictericus obtidos no periodo de 11 a 17 de janeiro de 2001, na área urbana e rural de Corupá, Santa Catarina.

\begin{tabular}{lcccccc}
\hline Areas & $\begin{array}{c}\text { Sapos } \\
\text { examinados }\end{array}$ & $\begin{array}{c}\text { Sapos } \\
\text { infestados }\end{array}$ & $\begin{array}{c}\text { Número de } \\
\text { carrapatos }\end{array}$ & $\begin{array}{c}\text { Intestação (a) } \\
\text { (\%) }\end{array}$ & $\begin{array}{c}\text { Densidade } \\
\text { relatıva (b) }\end{array}$ & $\begin{array}{c}\text { Intensidade da } \\
\text { intestação (c) }\end{array}$ \\
\hline Sudoeste & 57 & 11 & 149 & 19 & 2.6 & 13.5 \\
Sudeste & 31 & 5 & 11 & 16 & 0.4 & 2.2 \\
Noroeste & 23 & 5 & 11 & 22 & 0.5 & 2.2 \\
Nordeste & 14 & 3 & 7 & 21 & 0.5 & 2.3 \\
\hline Total & 125 & 24 & 178 & 19,2 & 1.4 & 7.4 \\
\hline
\end{tabular}

(a) Percentagem de hospedeiros infestados, (b) número de carrapatos/número de sapos examinados, (c) número de carrapatos/número de sapos infestados.

infestação nos machos (machos parasitados/machos examinados) foi de 24\%. Este fato foi também observado por LAMPO \& BAYLISS (1996) para B. marinus infestados principalmente com $A$. dissimile.

Os índices de infestação verificados para o sapo B. ictericus, no presente estudo. com intensidade média de infestação de 7.4 carrapatos/sapo, foram altos, quando comparados ao trabalho de LAMPO \& BAYLISS (1996) para B. marinus, cuja intensidade média de infestação foi de 2,48 carrapatos/sapo.

Durante o período de amostragem, foram encontrados alguns exemplares de sapos B. crucifer Wied, 1821, sendo que nenhum deles apresentou infestação por carrapatos. Esta espécie tem hábitos alimentares similares a B. ictericus c vive 
próximo de áreas preservadas de floresta, no interior da qual é comumente encontrado durante o dia. O maior número de exemplares foi verificado na região sudoeste $(\mathrm{N}=6)$, sendo também encontrado na região sudeste $(\mathrm{N}=1)$ e noroeste $(\mathrm{N}=1)$.

O elevado índice de infestação verificado para a região sudoeste, área mais rural (Tab. I), poderia ser explicado pelo fato dos sapos desfrutarem, com freqüência, os mesmos abrigos, uma vez que há fartura de alimento junto aos postes de iluminação. Por outro lado, as chances de infestação aumentam, já que os carrapatos compartilham o mesmo micro-hábitat com o hospedeiro, onde as condições são favoráveis ao seu desenvolvimento.

Alguns registros de A. rotundatum para o sul do Brasil e Argentina, referemse a animais exóticos (répteis, em cativeiro) como hospedeiros (ARAGÃo 1936; EVANS et al. 2000). Este é o primeiro registro de A. rotundatum em sapos da espécie B. ictericus. No trabalho de ARAGÃo (1936) é citada a ocorrência do carrapato $A$. rotundatum no Estado de Santa Catarina, para o município de Florianópolis, sem menção do hospedeiro.

AGRADECIMENTOS. Em especial, à Fundação O Boticário de Proteção a Natureza que patrocina o projeto: "Crianças salvando os anfíbios e a mata atlântica", do qual este trabalho faz parte. À Elza Nishimura Woehl que auxiliou nos trabalhos de campo. Aos alunos e professores da rede pública de ensino e residentes de Corupá pelo acolhimento e apoio. À Secretaria Municipal de Educação de Corupá, pelo grande apoio no trabalho realizado no ano passado com todos os alunos do município sobre fauna anfíbia da mata atlântica, projeto este, também patrocinado pela Fundação $\mathrm{O}$ Boticário de Proteção à Natureza, que trouxe à tona o problema da mortandade de sapos B. ictericus. A Rodrigo H.F. Teixeira, do Parque Zoológico Municipal Quinzinho de Barros, Sorocaba e à Marinete Amorim do Instituto Osvaldo Cruz, Rio de Janeiro, que gentilmente providenciaram a identificação dos carrapatos.

\section{REFERÊNCIAS BIBLIOGRÁFICAS}

Amorim, M; G.S. Gazêta; R.S. Cristalli \& N.M. Serra-Freire. 1996. Biology of Amblyomma rotundatum Koch, 1844 (Acari: Ixodidae) under laboratory conditions: infestation dynamics of unengorged female in Crotalus durissus (L.). Rev. Univ. Rural, Sér. Ci. Vida, Rio de Janeiro, 18 $(1 / 2): 35-39$.

Amorim, M.; G.S. Gazêta; A.S.L. Peralta; R.H.F. Teixeira \& N.M. Serra-Freire. 1998. Tick fauna of the Chelonia from Brazil. Rev. Univ. Rural, Sér. Ci. Vida, Rio de Janeiro, 20 (1/2): 31-35.

ARAGÃo, H.B. 1936. Ixodidas brasileiros e de alguns países limítrofes. Mem. Inst. Oswaldo Cruz 31 (4): 759-843.

ARAGĀo, H.B. \& F. FonSECA. 1961. Notas de Ixodologia. VIII. Lista e chave para os representantes da fauna ixodológica brasileira. Mem. Inst. Oswaldo Cruz 59: 115-129.

Evans, D.E.; J.R. Martins \& A.A. Guglielmone. 2000. A review of the ticks (Acari, Ixodida) of Brazil, Their Hosts and Geographic Distribution - 1. The State of Rio Grande do Sul, Southern Brazil. Mem. Inst. Oswaldo Cruz 95 (4): 453-470.

Frost, D.R. 2000. Amphibian Species of the World. Referência on-line disponível em: http://research.amnh.org/herpetology/amphibia/index.htm.

Heyer, W.R.; A.S. Rand; C.A.G. Cruz; O.L. Peixoto \& C.E. Nelson. 1990. Frogs of Boracéia. Arq. Zool., São Paulo, 31 (4): 231-410.

Kwet, A. \& M. Di-Bernardo. 1999. Pro-Mata - Anfibios. Amphibien. Amplibians. Porto Alegre, 
EDIPUCRS, 107p.

LAMPO, M. \& P. BAYLISs. 1996. The impact of ticks on Bufo marinus from native habitats. Parasitology 113: 199-206.

MATtison, C. 1994. Frogs and toads of the word. New York, Facts on File Inc., 191p.

OвA, M.S.P. \& T.T.S. Schumaker. 1983. Estudo da biologia de Amblyomma rotundatum (Koch, 1844), em infestações experimenatis de Bufo marinus (L. 1758) sob condições variadas de umidade relativa e de temperatura de ar. Mem. Inst. Butantã, São Paulo, 47/48: 195-204.

RoHR, C.J. 1909. Estudos sobre Ixodidas do Brasil. Trabalhos do Instituto Osvaldo Cruz. Rio de Janeiro, Gomes \& Irmãos, 220p.

Zug, G.R. \& P.B. Zug. 1979. The marine toad, Bufo marinus: a natural history resumé of native populations. Smiths. Contrib. Zool. 284: 1-58.

Recebido em 15.VI.2001; aceito em 26.IV.2002. 